\title{
A Community study of obstructive sleep apnea hypopnea syndrome (OSAHS) in middle-aged Bangladeshi population
}

\author{
Mosharraf-Hossain $\mathrm{AKM}^{1}$, Ahmed $\mathrm{K}^{2}$, Islam $\mathrm{MT}^{3}$, Chakrabortty $\mathrm{R}^{1}$ \\ 1. Respiratory Medicine, Bangabandhu Sheikh Mujib Medical University, Dhaka, 2. Department of Obstetric \& \\ Gynaecology, Mymensingh Medical College and Hospital, Mymensingh, 3. Internal Medicine, \\ Bangabandhu Sheikh Mujib Medical University, Dhaka. \\ Email: akmmosharrafhossain@yahoo.com
}

\begin{abstract}
Obstructive sleep apnea hypopnea syndrome (OSAHS) is the occurrence of repetitive episodes of complete or partial upper airway obstruction during sleep in association with loud snoring and daytime sleepiness and is a risk factor for hypertension, cardiovascular and cerebrovascular diseases and more. The present study was performed to assess the prevalence as well as the clinical and anthropometric predictors of OSAHS in an urban community of middle aged Bangladeshi population. The study was a cross-sectional, community-based prevalence study which was performed in an urban community in Dhanmondi Thana Pourashava of Dhaka city from July 2007 to June 2008. About 2500 citizens, aged 30-60 years were included in the study. In stage one of the study, they were informed about the polysomnography (PSG) study (stage two of the study) and 2250 of them gave consent. Subjects were then divided into habitual (495) and non-habitual snorers (1755). Among 2250 subjects, the prevalence of obstructive sleep apnea hypopnea (OSAH) in habitual snorers was $48.33 \%$ (239/495), and that in non-habitual snorers was $1.66 \%(29 / 1755)$. So, the overall prevalence of OSAH in the screened population was $11.91 \%$, and that of OSAHS was $3.29 \%$. Likewise, the prevalence of OSAH and OSAHS in men were $17.37 \%$ and $4.49 \%$, respectively and $6.25 \%$ and $2.14 \%$ in women. Multivariate analysis revealed that male gender, age, obesity (defined by a high body mass index), waist/hip ratio were significant risk factors for OSAHS. These findings can help us in identifying the prevalence of OSAHS in the community and further planning in the management of obesity and cardiovascular diseases.
\end{abstract}

\section{Introduction}

Sleep related breathing disorders are common in all age groups and result in significant morbidity and mortality. According to International classification of sleep disorders, version 2(ICSD-2), the term obstructive sleep apnea (OSA) includes those sleep related breathing disorders in which there is an obstruction in the airway resulting in increased breathing effort and inadequate ventilation. ${ }^{1}$ The term OSA syndrome has been introduced initially to describe this condition with its central feature of day time hypersomnolence and polysomnographically proven obstructive apneas. ${ }^{2}$ After hypopnea has been described as respiratory events of shallow breathing causing oxygen desaturation, ${ }^{3}$ the OSAH syndrome has been referred to as obstructive sleep apnea hypopnea syndrome (OSAHS) . ${ }^{4}$ So, OSAHS is characterized by recurrent episodes of complete or partial upper airway obstruction during sleep, in conjunction with daytime sleepiness ${ }^{4}$ and respiratory events as measured by polysomnography (PSG) criteria.

Epidemiology of OSAH has been illustrated from large prospective community based studies especially in western countries. The prevalence of OSAHS has been reported to be between $0.3 \%$ and $7.5 \%$ in the general population in different studies, ${ }^{5,6}$ depending on the differences in OSAH definitions used and the population selected. There is paucity of data from Asian countries on the epidemiology of OSAH. The prevalence of OSAH among Korean adults was $27 \%$ and $16 \%$ in men and women and OSAHS was $4.5 \%$ and $3.2 \%$ in men and women respectively. ${ }^{7}$ In semi-urban Indian, the prevalence of OSAH and OSAHS were $13.74 \%$ and $3.57 \%$ respectively. ${ }^{8} \mathrm{~A}$ number of risk factors have been found to be associated with OSAH in different studies. Obesity has been identified as a strong risk factor. ${ }^{9-14}$ Male gender, ${ }^{12}$ age, ${ }^{13}$ smoking and alcohol intake ${ }^{14}$ have been found to be independent correlates of the apneahypopnea index (AHI). The OSAH is independently associated with several CVD, including hypertension, ischemic heart disease, atrial fibrillation, cerebrovascular disease, and heart failure. ${ }^{15}$ Moreover, people with OSAH seem to exhibit a peak in sudden death from cardiac causes during the sleeping hours. ${ }^{16}$ These patients suffer from impaired work performance, irritability, 
marital disharmony, and reduced participation in and enjoyment of everyday activities. ${ }^{17}$ AHI of five or greater is significantly associated with selfassessed concentration problems but not with memory. ${ }^{18}$

Bangladesh is a country in south-east Asia with population 149.8 million in an area of $147,570 \mathrm{sq}$ $\mathrm{km}$ with life expectancy 66.6 years and 68.8 years in male and female respectively. ${ }^{19} \mathrm{~A}$ single bedded standard PSG laboratory was established at private level in 23rd June, 2005. Since then overnight standard PSG studies are performed under the supervision of the investigator. In a pilot study ${ }^{20}$ [N: 96; sex (male/female): 66/30]; age [(yrs, $\mathrm{m} \pm \mathrm{SD}$ ): $33 \pm 8$ ] using the Berlin questionnaire and Epworth sleepiness scale (ESS) among Bangladeshi adult in 2004, snoring and day time sleepiness was observed in $35 \%$ and $46 \%$ respectively. Both witness apnea and wake time tiredness was seen in $25 \%$. About $41 \%$ subjects showed ESS score $>10$. In another preliminary study, ${ }^{21} 63$ consecutive clinically suspected OSAH patients were included. Among them 58 patients [age: $(\mathrm{M} \pm \mathrm{SD}) 47 \pm 11.55$ in yrs; sex: (m/f) 42/16] underwent in-laboratory noctunal polysomnography (NPSG). Structured sleep interview, anthropometric measurement and nocturnal polysomnography (NPSG) were performed in all subjects. Presence of OSAHS was defined when apnea hypopnea index was five or more (AHI >5) with excessive daytime sleepiness (EDS). In that PSG based study, ${ }^{21}$ snoring, witness apnea, leg movements in sleep, dry throat, nocturia and ESS were shown to have significant relationship with OSAHS. Multiple regression analysis showed body mass index (BMI), snoring and Ehlers danlos syndrome (EDS) as independent predictors of OSAHS.

There had been no standard overnight polysomnography (PSG) based community study to assess the prevalence of OSAH and OSAHS in Bangladesh. The present study was performed to assess the prevalence as well as clinical and anthropometric predictors of OSAHS in an urban community of middle aged Bangladeshi population.

\section{Materials and Methods}

The study was a cross-sectional, community-based prevalence study performed in an urban community in Dhanmondi Thana Pourashava of Dhaka city in the duration from July 2007 to June 2008. Total 2500 citizens, aged 30-60 years, in the Dhanmondi residential area were included in the study. There are five wards in the Dhanmondi police station. The wards were selected by lottery method. Five hundred participants were recruited randomly from each ward. The sampling was conducted in a houseto-house manner randomly in person by the interviewer. An awareness of the disease was created in the area by distributing an article published in a Bengali Health megazine by the investigator himself. A written informed consent form was obtained from the participants who finally agreed to participate in the study. A subject was excluded from the study, if he or she had history of recent myocardial infarction, severe acute asthma, severe chronic obstructive pulmonary disease (COPD), upper airway surgery, class III/IV congestive heart failure, respiratory failure, pregnancy, hypothyroidism on treatment, acromegaly, chronic renal failure, systemic steroid treatment, hormone replacement therapy and disorders including craniofacial abnormality.

Stage one of the study consisted of the administration of the sleep questionnaire and brief anthropometric measurements. A modified version of the Wisconsin sleep cohort questionnaire ${ }^{6}$ was translated and validated into Bengali language. The questionnaire included questions about demographics, sleeps symptoms, medical history, and medications. A 4-point scale was used for quantifying snoring and sleep-related choking. A score of 0 indicated never, a score of 1 indicated a frequency of less than once per week, a score of two indicated a frequency of once or twice per week, a score of three indicated a frequency of three or four times per week, and a score of four indicated a frequency of more than four times a week. Based on this score, habitual snoring was defined as a score of $>3$ point for snoring or choking. Habitual smoking 22 was defined as current smoking of $>10$ cigarettes per day for $>10$ years, and habitual drinking was denied as the consumption of $>100 \mathrm{~g}$ of alcohol per day for $>10$ years. ${ }^{23}$ A limited physical examination was performed in which height, weight, BMI, neck circumference (NC), waist and hip ratio (WHR), and BP were measured according to standard methods ${ }^{24}$. Subjects were classified as obese when the BMI was $>25 \mathrm{~kg} / \mathrm{m} .{ }^{25} \mathrm{~A}$ WC of $>102 \mathrm{~cm}$ in men and $>88 \mathrm{~cm}$ in women, ${ }^{26}$ and a WHR of $>0.95$ in men and $>0.88$ in women were used as parameters of obesity in the analysis. ${ }^{27}$

In stage two of the study, the data from the questionnaires were analyzed, and the respondents were divided as per their snoring habits into habitual and non-habitual snorers. In view of the economic resources available to the investigator, 60 habitual snorers and equal number of non-habitual snorers were selected randomly for PSG. Polysomnography studies were conducted at the sleep laboratory in a private clinic. A fully computerized PSG device (Compumedics, E series) was used with 16 channels recordings and in accordance with standard 10-20-20 electrode 
placement. They documented parameters including electroencephalography (EEG), electrooculography, electromyography (EMG), electrocardiography (ECG), respiratory effort, nasal and oral airflow, arterial oxyhemoglobin saturation $\left(\mathrm{SpO}_{2}\right)$ and snoring, body position, PSG records were scored manually by the investigator according to standard Rechtschaffen and Kales criteria. ${ }^{28}$ An apnea was defined as complete cessation of airflow lasting $>10$ s with discernible thoraco-abdominal movement and a hypopnea was defined as reduction in airflow accompanied by a decrease of $>4 \%$ in oxy-hemoglobin saturation. ${ }^{4}$ The apneahypopnea index (AHI) was calculated as the average number of apnea and hypopnea events per hour of sleep. Arousals was defined according to established criteria. ${ }^{29}$ The subjective complaint of EDS was measured by questionnaire called the Epworth Sleepiness Scale (ESS). ${ }^{36}$ The subject was considered to have EDS if the ESS score is $>10$. In this study, OSAH was defined as AHI $>5$ and OSAHS was defined as AHI $>5$ with presence of EDS.

A structured questionnaire was used to collect data concerning demographic data, sleep habits, snoring history, breathing irregularities and leg movements during sleep, daytime sleepiness, smoking and drinking history, medical history, family history of sleep apnea, and job nature. Measures of body habitus was recorded by standard anthropometric methods. The overall prevalence of SDB in the entire cohort was calculated as [the estimated number of subjects with OSAH among habitual snorers and non-habitual snorers/(total number of questionnaire respondents X 100\%)]. Descriptive statistics was used to summarize subject characteristics and questionnaire data. Comparison between groups were done with the Student's t test for continuous variables and Pearson's $\chi^{2}$ test for discrete variables. All significance tests were two sided, and a value of $\mathrm{p}<0.05$ was considered statistically significant. To adjust the effect of various factors on the likelihood of developing snoring and OSAHS, a multiple logistic regression analysis was employed. All analysis was done with statistical software (Statistical Package for the Social Sciences, release 12.0 for Windows; SPSS).

\section{Results}

A descriptive flow chart of the studied populations are presented in the Figure 1. The mean $( \pm \mathrm{SD})$ age of the study population was $39.77 \pm 9.41$ years and most of the subjects in the study were from a middle class socioeconomic (SEC) background. The subjects had a mean BMI of $23.54 \pm 3.49 \mathrm{~kg} / \mathrm{m}^{2}$ (range, 16.4 to $30.8 \mathrm{~kg} / \mathrm{m}^{2}$ ). The percentage of habitual snorers in the study population was $22 \%$.

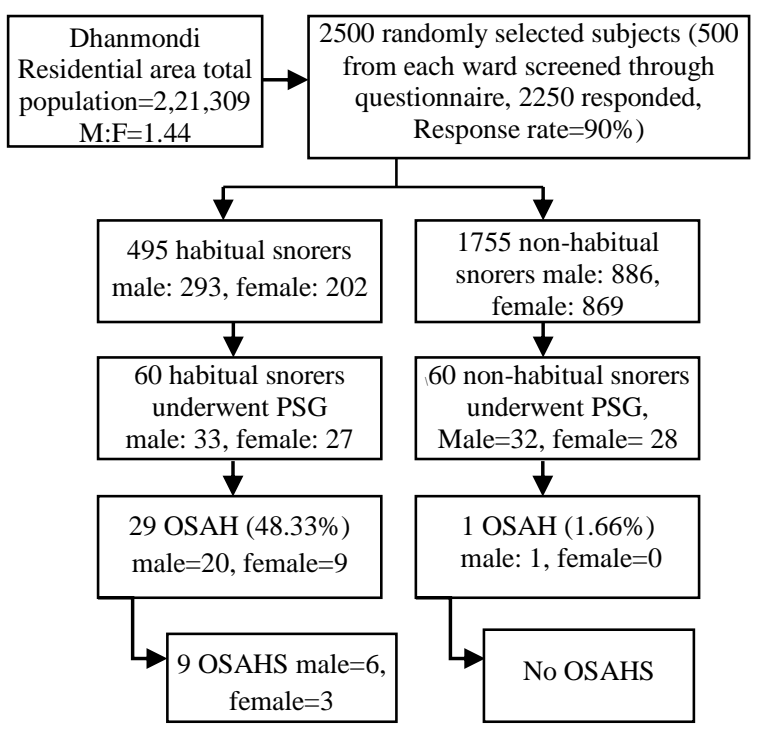

Fig.1: Flow chart of the study

The demographic characteristics of the study population are summarized in Table I. 60(12.12\%) out of 495 screened habitual snorers and 60(3.41\%) out of 1,755 nonhabitual snorers were randomly called for polysomnography. From the 120 polysomno-graphy studies conducted, random selection of candidates for polysomnography studies ensured that the subset of patients that underwent polysomnography was similar to the larger cohort that did not undergo polysomnography.

Among the 120 subjects who underwent polysomnography, 30 subjects had OSAH (habitual snorers, 29 subjects; nonhabitual snorers, 1 subject). The prevalence of OSAH in habitual snorers was $48.33 \%$ (239/495), and that in nonhabitual snorers was $1.66 \%$ (29/1755). So, the overall prevalence of OSAH in the screened population was $11.91 \%$, and that of OSAHS was $3.29 \%$. Likewise, the prevalences of OSAH and OSAHS in men were $17.37 \%$ and $4.49 \%$, respectively and $6.25 \%$ and $2.14 \%$ in women.

Table I: Demographic Profile of the Study Population $(n=2,250)^{*}$

\begin{tabular}{ll}
\hline Variables & Values \\
\hline Age(year) & $39.77 \pm 9.41$ \\
Male/female ratio & 1.22 \\
Weight $(\mathrm{kg})$ & $61.7 \pm 13.9$ \\
Height $(\mathrm{cm})$ & $158.4 \pm 9.4$ \\
BMI $\left(\mathrm{kg} / \mathrm{m}^{2}\right)$ & $23.54 \pm 3.49$ \\
Habitual snorers & $495(22)$ \\
Habitual smoking & $560(24.88)$ \\
Habitual drinking & $34(1.5)$ \\
Hypertension & $562(24.97)$ \\
Middle SEC & $1379(61.28)$ \\
\hline
\end{tabular}

( ${ }^{*}$ Values are given as the mean $\pm \mathrm{SD}$ or No. $(\%)$, unless otherwise indicated)

The results of univariate analysis are shown in Table II. The profiles of OSAH and non-OSAH subjects are compared in Table III. The mean age of the subjects undergoing polysomnography was 
$39.50 \pm 6.45$ years, with $57.5 \%$ men (69/120) participating. The BMI ranged from 15.8 to 39.8 $\mathrm{kg} / \mathrm{m}^{2}$, with a mean of $25.9 \pm 4.7 \mathrm{~kg} / \mathrm{m}^{2}$. The male gender and various parameters of obesity such as BMI of $>25 \mathrm{~kg} / \mathrm{m}^{2}$, WC of $>102 \mathrm{~cm}$ in men and $>88$ in women, WHR of $>0.95$ in men and $>0.8$ in women, and NC showed significant correlation with AHI. OSAH was found to be more common in subjects of upper socioeconomic classes (SECs). The prevalence of hypertension was greater in OSAH subjects, although the difference was not significant. Smoking and alcohol consumption were more common in OSA subjects.

Table II: Univariate Analysis of Habitual and Nonhabitual Snorers*

\begin{tabular}{lccc}
\hline \multicolumn{1}{c}{ Variables } & $\begin{array}{c}\text { Habitual } \\
\text { snorers } \\
(\mathrm{n}=495)\end{array}$ & $\begin{array}{c}\text { Nonhabitual } \\
\text { snorers } \\
(\mathrm{n}=1,755)\end{array}$ & OR $(95 \% \mathrm{CI})$ \\
\hline Weight(kg) & $70.15 \pm 12.98$ & $58.81 \pm 13.06$ & $4.79(3.89-5.91)$ \\
Height $(\mathrm{cm})$ & $159.82 \pm 8.99$ & $157.88 \pm 9.46$ & $1.25(1.03-1.51)$ \\
BMI $\left(\mathrm{kg} / \mathrm{m}^{2}\right)$ & $27.49 \pm 4.85$ & $23.60 \pm 4.91$ & $3.97(3.24-4.87)$ \\
NC(cm) & $36.44 \pm 3.28$ & $34.16 \pm 3.37$ & $3.36(2.75-4.10)$ \\
Obesity (WC) & $307(55.4)$ & $438(27.4)$ & $3.29(2.69-4.02)$ \\
Obesity(WHR) & $375(67.7)$ & $617(38.7)$ & $3.32(2.71-4.08)$ \\
Hypertension & $276(49.8)$ & $460(28.8)$ & $2.45(2.01-2.99)$ \\
Systolic BP & $135.84 \pm 19.42$ & $126.98 \pm 18.38$ & $3.82(2.38-5.26)$ \\
(mmHg) & & & \\
Diastolic BP & $87.14 \pm 1.42$ & $82.16 \pm 10.27$ & $2.55(2.09-3.11)$ \\
(mmHg) & & & \\
Age(year) & $44.24 \pm .96$ & $41.24 \pm 9.4$ & $1.75(1.44-2.13)$ \\
Male/female ratio & 1.45 & 1.01 & $1.43(1.18-1.74)$ \\
Upper SEC & $61(11.02)$ & $165(10.34)$ & $1.07(0.79-1.47)$ \\
Habitual smoking & $167(24.9)$ & $393(20.3)$ & $1.30(1.04-1.64)$ \\
Habitual drinking & $61(11.01)$ & $73(4.57)$ & $2.58(1.81-3.68)$ \\
\hline
\end{tabular}

(*Values are given as the mean \pm SD or No. $(\%)$, unless otherwise indicated. $\mathrm{p}<0.001, \mathrm{p}<0.05)$

Table III: Comparison of Demographic, Anthropometric, and Socioeconomic Profile Between OSAH and non-OSAH Subjects With Unadjusted ORs*

\begin{tabular}{lcccc}
\hline Variables & $\begin{array}{c}\text { OSAH } \\
\text { subjects } \\
(\mathrm{n}=30)\end{array}$ & $\begin{array}{c}\text { Non- } \\
\text { OSAH } \\
\text { subjects } \\
(\mathrm{n}=90)\end{array}$ & $\begin{array}{c}\mathrm{p} \\
\text { value }\end{array}$ & OR (95\%CI) \\
\hline Male/female ratio & 2.33 & 1.03 & 0.003 & $3.5(1.5-8.3)$ \\
Age(year) & $46.7 \pm 9.3$ & $41.3 \pm 8.5$ & 0.001 & $4.8(2.2-10.2)$ \\
Upper SEC & $11(28.9)$ & $7(6.2)$ & 0.000 & $6.11(2.2-17.3)$ \\
BMI(kg/m²) & $29.5 \pm 4.2$ & $24.6 \pm 4.2$ & 0.000 & $15.3(5.1-46.2)$ \\
Obesity Defined by & $26(68.4)$ & $37(33.1)$ & 0.000 & $4.39(1.9-9.7)$ \\
WC & & & & \\
Obesity & $36(94.7)$ & $49(43.8)$ & 0.000 & $23.14(5.3-$ \\
Defined by WHR & & & & $100.9)$ \\
NC (cm) & $38.7 \pm 3.3$ & $35.8 \pm 3.5$ & 0.000 & $4.9(2.35-10.9)$ \\
Habitual smoking & $8(21.1)$ & $8(7.1)$ & 0.016 & $3.5(1.2-10)$ \\
Habitual drinking & $5(13.2)$ & $3(2.7)$ & 0.013 & $5.51(1.3-24.3)$ \\
Habitual snoring & $36(94.7)$ & $41(36.6)$ & 0.000 & $31.2(7.1-136.8)$ \\
ESSscore & $7.3 \pm 4.2$ & $1.9 \pm 1.6$ & 0.000 & $65.2(18-236.2)$ \\
Hypertension & $17(44.7)$ & $31(27.7)$ & 0.05 & $2.1(0.9-4.5)$ \\
Systolic BP(mmHg) & $138.8 \pm 13.2$ & $130.1 \pm 13.3$ & 0.001 & $3.9(1.8-8.5)$ \\
Diastolic BP(mmHg) & $88.2 \pm 9.4$ & $83.7 \pm 10.1$ & 0.018 & $2.8(1.3-5.9)$ \\
\hline [*Values are given as the mean \pm SD or No.(\%)] &
\end{tabular}

The polysomnography data are provided in Table IV. It shows that slow-wave sleep (stage III and stage IV) and rapid eye movement (REM) sleep constituted the lesser part of total sleep time in subjects with OSA compared to non-OSA subjects. There was a significant difference in total sleep time, wake time after sleep onset, and arousal index, but no significant difference in sleep onset or REM onset latency in the two groups.

Table IV: Comparison of Polysomnography Parameters in the OSA and Non-OSA Groups*

\begin{tabular}{lccc}
\hline Variables & $\begin{array}{c}\text { OSA subjects } \\
(\mathrm{n}=30)\end{array}$ & $\begin{array}{c}\text { Non-OSA } \\
\text { subjects } \\
(\mathrm{n}=90)\end{array}$ & $\begin{array}{c}\mathrm{P} \\
\text { value }\end{array}$ \\
\hline Total sleep time(min) & $\begin{array}{c}360.5 \\
(312.5-422.5)\end{array}$ & $\begin{array}{c}405.5 \\
(365-445.3)\end{array}$ & 0.03 \\
Total wake time(min) & $97.5 \pm 13.9$ & $76.38 \pm 19.2$ & 0.001 \\
Wake time after sleep onset & $74.4 \pm 15.2$ & $44.32 \pm 6.8$ & 0.000 \\
(min) & & & \\
Sleep time & $74.2 \pm 4.5$ & $82.3 \pm 5.6$ & 0.004 \\
Sleep onset latency(min) & $28.8 \pm 6.7$ & $26.4 \pm 5.4$ & 0.16 \\
REM onset latency(min $)$ & $71.3 \pm 11.7$ & $68.5 \pm 12.8$ & 0.38 \\
Sleep architecture & & & \\
Stage 1 sleep & $26.8 \pm 5.9$ & $22.4 \pm 6.2$ & 0.006 \\
Stage 2 sleep & $43.9 \pm 6.9$ & $36.5 \pm 7.9$ & 0.002 \\
Slow-wave sleep & $16.3 \pm 5.2$ & $26.6 \pm 5.6$ & 0.000 \\
REM sleep & $13.1 \pm 4.1$ & $14.5 \pm 6.84$ & 0.23 \\
Minimum oxygen saturation & $73.2 \pm 6.8$ & $91.2 \pm 2.3$ & 0.000 \\
Sao2<90\%(min) & $26.4 \pm 5.9$ & $2.13 \pm 0.6$ & 0.000 \\
Arousal index(arousals/h) & $11.8 \pm 2.3$ & $6.4 \pm 1.9$ & 0.002 \\
\hline
\end{tabular}

$*$ Values are given as the mean $\pm \mathrm{SD}, \mathrm{SaO}_{2}=$ arterial oxygen saturation.

The variables, which significantly affected the presence of OSA, were included in multiple logistic regression analyses, which are shown in Table V. They included male gender, age $>45$ years, upper SEC, obesity defined by a BMI of $>25 \mathrm{~kg} / \mathrm{m} 2$, and WHR of $>0.80$ in women and $>0.95$ in men as significant risk factors for OSA.

Table V: Multivariate Analysis of Risk Factors for OSA.

\begin{tabular}{ll}
\hline Variables & Multivariate analysis \\
\hline Male gender & $10.32(3.07-34.7)$ \\
Age $>45$ & $3.32(1.13-9.76)$ \\
Upper SEC & $6.04(1.31-28)$ \\
BMI $>25\left(\mathrm{~kg} / \mathrm{m}^{2}\right)$ & $4.98(2.4-69.83)$ \\
WHR & $12.94(2.4-69.83)$ \\
\hline
\end{tabular}

(values are given as OR, 95\%CI)

\section{Discussion}

The present study represents the first population based survey of OSAH in Bangladesh. The burden of the disease appears to be fairly high. The overall prevalence of OSAH was $11.91 \%$, and that of OSAHS was $3.29 \%$. Likewise, the prevalence of OSAH and OSAHS in men were $17.37 \%$ and $4.49 \%$, respectively. The prevalence of OSAH and OSAHS in women was $6.25 \%$ and $2.14 \%$ respectively. Male gender, age, obesity defined by a high BMI, and WHR stood out as independent risk factors for OSAH.

Prevalence of OSAH: In terms of OSAH prevalence, our findings fall within the range of 
previously published rates. Young and colleagues ${ }^{6}$ reported the prevalences of OSAHS as $2 \%$ and $4 \%$, respectively, for women and men. Moreover, the prevalences of OSAHS in middle-aged men and women from Hong Kong were reported to be $4.1 \%$ and $2.1 \%$, respectively. ${ }^{13}$ In India, Udwadia and colleagues $^{1}$ studied urban men between 35 and 65 years of age presenting to the hospital for routine checkup, and reported the estimated prevalence of OSAH as $19.5 \%$ and that of OSAHS as $7.5 \%$. However, because of methodological issues, including significant selection bias in terms of gender as well as socioeconomic status of the recruited subjects, the results of this study cannot be extrapolated to the general population. Moreover, they performed home sleep studies using a portable limited polysomnography machine. Intriguingly, the prevalence rates of OSA appear to be comparable in Chinese, American, and Indian populations, despite the postulated differences in cephalic characters and the prevalence of obesity in these nationalities. It is obvious that the development of OSAH is a culmination of the interplay of several characteristics apart from obesity and cephalic parameters.

Risk Factors for OSA: Male gender was associated with a 10-fold higher risk of having OSAH. Earlier studies $^{13}$ have consistently reported a higher prevalence of OSA in men. Ratios as high as 10:1 in favor of men have been reported ${ }^{4}$ while studying sleep apnea in clinical settings. Although their findings were novel at the time, the sample was probably too small for a prevalence study. There are several reasons for the observed differences in the prevalence between men and women. These include differences in the distribution of adipose tissue, upper-airway anatomy and muscle function, control of ventilation, and the effects of sex hormones and leptin. ${ }^{30}$ The gender related protective effect decreases in postmenopausal women who are not receiving hormone replacement therapy. ${ }^{31,32}$ The higher male preponderance shown in the current study could be due partly to the higher number of men among the subjects who underwent polysomnography studies. Age was also determined to be an independent predictor of OSAH. Older subjects (i.e., >45 years of age) had more than three times the increased risk of having OSAH. The correlation between age and OSAH has been studied by various researchers, yielding disparate results with a suggestion of a rise in the prevalence of OSA with age. Ip and colleagues ${ }^{13}$ found that the prevalence of OSA tends to rise in the older population and that this was independent of obesity. However, some researchers ${ }^{4,6,11}$ have concluded that this effect occurs only to middle age and that age ceases to be an independent risk factor for OSAH beyond middle age. SEC was another independent risk factor for OSAH, with higher SEC associated with increased risk. However, this must be viewed with the understanding that the majority of persons in our study population hailed from middle class backgrounds and a very small segment was from upper class backgrounds. The small segment of upper class individuals is probably not sufficient to make strong interpretations of the relationship between OSAH and SEC. We suggest that investigators might consider including SEC as a confounder variable in their models in future studies. Obesity has been an important modifiable risk factor in the occurrence of OSAH. ${ }^{33-36}$ We used different parameters for obesity and studied them for their association with OSA. Among these parameters, BMI and WHR were independent predictors of OSA. Most Western studies have used a BMI of $>30 \mathrm{~kg} / \mathrm{m}^{2}$ as the upper limit for the definition of obesity. However, a different definition (ie, BMI $>25 \mathrm{~kg} / \mathrm{m}^{2}$ ) as recommended by the World Health Organization was used. Notably, other parameters of obesity, such as WC, NC did not have any independent association with OSA.

\section{Acknowledgement/Conflict of interest}

It is funded by Bangladesh Medical Research Council, Mohakhali, Dhaka.

\section{References}

1. Thorpy MJ. Classification of Sleep disorders. In: Kryger MH, Roth T, Dement WC, editors. Principles and Practice of Sleep Medicine, Philadelphia Saunders; 2005:1109-21.

2. Guilleminault C, Tilkian A, and Dement WC. The sleep apnea syndromes. Annu Rev Med 1976; 27: 46584.

3. Block AJ, Boysen PG, Wynne JW, Hunt LA. Sleep apnea, hypopnea and oxygen desaturation in normal subjects: a strong male predominance. $\mathrm{N}$ Engl $\mathrm{J}$ Med 1979; 300: 513-17.

4. Sleep related breathing disorders in adults: recommendation for syndrome definition and measurement technique in clinical research. The report of American Academy of Sleep medicine Task force. Sleep 1999; 22: 667-89.

5. Stradling JR, Crosby JH. Predictors and prevalence of obstructive sleep apnoea and snoring in 1001 middle aged men. Thorax 1991; 46: 85-90

6. Young T, Palta M, Dempsey J, Skatrud J, Weber S, Badr S. The occurrence of sleep-disordered breathing among middle-aged adults. N Engl J Med 1993; 328: 1230-35.

7. Kim JK, In KH, Kim JH, You SH, Kang KH, Shim JJ, et al. Prevalence of sleep disordered breathing in middle aged Korean men and women. Am J Respir Crit Care Med 2004, 170: 1108-13. 
8. Sharma SK, Kumpawat S, Banga A, Goel A. Prevalence and Risk Factors of Obstructive Sleep Apnea Syndrome in a Population of Delhi, India. Chest 2006; 130: 149-56.

9. Deegan PC, McNicholas WT. Predictive value of clinical features for the obstructive sleep apnoea syndrome. Eur Respir J 1996; 9: 117-24.

10. Seidell JC. Obesity, insulin resistance and diabetes: a worldwide epidemic. Br J Nutr 2000 ; 83(suppl):S5-S8

11. Schafer H, Pauleit D, Sudhop T, Gouni-Berthold I, Ewig S, Berthold HK. Body fat distribution, serum leptin, and cardiovascular risk factors in men with obstructive sleep apnea. Chest 2002; 122: 829-39.

12. Ip MS, Lam B, Tang LC, Lauder IJ, Ip TY, Lam WK. A community study of sleep-disordered breathing in middle-aged Chinese women in Hong Kong: prevalence and gender differences. Chest 2004; 125: 127-34.

13. Ip MS, Lam B, Lauder IJ, Tsang K, Chung K, Mok Y, et al. A community study of sleep disordered breathing in middle-aged Chinese men in Hong Kong. Chest 2001; 119: 62-69.

14. Coughlin SR, Mawdsley L, Mugarza JA, Calverley PM, Wilding JP. Obstructive sleep apnoea is independently associated with an increased prevalence of metabolic syndrome. Eur Heart J 2004; 25:735-41.

15. Mosharrof-Hossain AKM, Pasha MM. Obstructive sleep apnea and cardiovascular effect, University Heart Journal 2008; 4(2): 41-45.

16. Gami AS, Howard DE, Olson EJ, Somers VK. Daynight pattern of sudden death in obstructive sleep apnea. N Engl J Med 2005; 352: 1206-14.

17. Engleman HM and Douglas NJ. Sleepiness, cognitive function, and quality of life in obstructive sleep apnoea/hypopnoea syndrome, Thorax 2004; 59: 61822.

18. Naegele B , Thouvard V, Pepin JL, Lévy P, Bonnet C, Perret JE, et al. Deficits of cognitive executive functions in patients with sleep apnea syndrome. Sleep 1995; 18: 43-52.

19. Bangladesh Bureau of Statistics (BBS). 2011; Available from http://www.bbs.gov.bd/WebTest Application/userfiles/Image/LatestReports/YB2011.pdf

20. Mosharraf-Hossain AKM, Hasanat MA, Chowdhury MAJ, Hasan M. Snoring and risk of sleep disordered breathing-a pilot study in Bangladesh. Chest 2004; 126: $904 \mathrm{~s}$

21. Mosharraf-Hossain AKM, Hadi H, Baki SA. Clinical predictors of sleep disordered breathing (SDB) in Bangladeshi adult population. Proceedings of the 5th Asian Sleep Research Society (ASRS) Seoul Congress, 2006 September 20-23, Korea; p 205.
22. Minami J, Ishimitsu T, Matsuoka H. Effect of smoking cessation on blood pressure and heart rate variability in habitual smokers. Hypertension 1999; 33: 586-90.

23. Hauge T, Persson J, Sjolund K. Neuropeptides in the duodenal mucosa of chronic alcoholic heavy drinkers. Alcohol and Alcoholism 2001;36: 213-18.

24. Sharma SK, Kurian S, Malik V, Mohan A, Banga A, Pandey RM, et al. A stepped approach for prediction of obstructive sleep apnea in overtly asymptomatic obese subjects: a hospital based study. Sleep Med 2004; 5: 351-57.

25. World Health Organization. The Asia Pacific perspective : redefining obesity and its treatment 2000. In: Institute ID, ed. Sydney, NSW, Australia: International Diabetes Institute, 2000.

26. Han TS, Van Leer EM. Waist circumference action levels in the identification of cardiovascular risk factors: prevalence study in a random sample. BMJ 1995; 311:1401- 05 .

27. Willet WC, Dietz WH, Colditz GA. Guidelines for healthy weight. N Engl J Med 1999; 341: 427-34.

28. Rechtschaffen A, Kales AA, eds. A manual of standardized terminology, techniques and scoring system for sleep stages of human subjects. Washington, DC: Government Printing Office, 1968; National Institutes of Health Publication No. 204.

29. American Sleep Disorders Association. EEG arousals: scoring rules and examples; ASDA report. Sleep 1992; 15:173-84

30. Kapsimalis F, Kryger MH. Gender and obstructive sleep apnea syndrome: part 2. Mechanisms. Sleep 2002; 25: 499-06.

31. Resta O, Caratozzolo G, Pannacciulli N, Stefàno A, Giliberti T, Carpagnano GE, et al. Gender, age and menopause effects on the prevalence and the characteristics of obstructive sleep apnea in obesity. Eur J Clin Invest 2003;33:1084-89.

32. Wilhoit SC, Suratt PM. Obstructive sleep apnea in premenopausal women: a comparison with men and with postmenopausal women . Chest 1987; 91:654-58.

33. Coughlin S, Calverley P, Wilding J. Sleep disordered breathing: new component of syndrome $\mathrm{X}$ ? Obes Rev 2001; 2: 267-74.

34. Jubber AS. Respiratory complications of obesity. Int $\mathbf{J}$ Clin Pract 2004; 58: 573-80.

35. Vgontzas AN, Bixler EO, Chrousos GP. Metabolic disturbances in obesity versus sleep apnoea: the importance of visceral obesity and insulin resistance. $\mathrm{J}$ Intern Med 2003; 254: 32-44.

36. Deegan PC, McNicholas WT. Pathophysiology of obstructive sleep apnoea. Eur Respir J 1995; 8: 1161-78. 